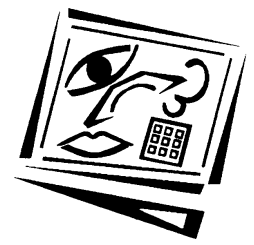

\title{
Digitalising our schools: Clarity and coherence in policy
}

\author{
Lorrae Ward \\ CYPERUS
}

Judy M Parr

University of Auckland

\begin{abstract}
While society has moved through a number of "ages" since the industrial age, many schools have remained firmly entrenched in an education system designed for a world which, largely, no longer exists. Educational policy and literature is replete with discourse related to school reform, 21st century learning and the importance of information and communication technologies (ICT). It is also replete with stories of failed reform initiatives. ICT is no exception. Internationally, there is little evidence of any real shift in the ways students experience learning, or that schools are becoming a digital environment rather than a paper-based one.
\end{abstract}

In this article, we argue that the lack of apparent success in promoting educational reform through ICT is due, at least in part, to a policy disconnect which exists where strategic discourse (goals, purposes, values) is translated into operational discourse (concerning activities and outcomes), rather than where operational discourse becomes operational practice (implementation in classrooms). The conclusion drawn is that operational discourse needs to make explicit the rationales underpinning ICT policy, and policy makers need to ensure that teachers are provided with the necessary opportunities to explore, challenge and change beliefs and practice.

\section{Introduction}

Within educational discourse talk of the shift from industrial age education to the knowledge and/or the digital age, where students have access to a wide range of information and resources and where digital tools are used in authentic learning situations, is commonplace. This shift is linked to the perceived need for educational reform and a focus on 21st century learning ideals. More recently, in the literature, talk has begun of the age of the network. The vision for schooling, in this age, includes a greater nexus between home and school learning; a breaking down of the notion of a school as a single building within which teaching and learning occurs; both of which are collaborative and socially networked (Lee, 2010).

However, the reality in schools is generally very different. While there are some 'pathfinder' schools, for most the processes of management and assessment continue to be barriers to a digital, let alone networked environment. Digital technologies (including ICTs) are often present but are not as evident in the learning experiences of students as they are in their wider lives. Many schools do not appear to have moved into the knowledge age, let alone the digital or networked one in that their structures, processes and operation remain largely based in the industrial age of last century. 
This is despite government policies and strategic intent documents around the world consistently espousing the importance of a digitally literate society and arguing for a shift in pedagogy to better reflect the 21st century. The political commitment to the digitalisation of schools has remained constant, despite the apparent lack of real success to date in changing the nature of the core functions of schooling: teaching and learning (for example see Hayes, 2007).

ICT strategic discourse, at a government level, often focuses on the education sector as the key agent for achieving wider society goals (Tondeur, van Braak \& Valcke, 2007), while educational discourse emphasises the importance of integrating ICT and elearning (Institute for Professional Development and Research, 2002). In 1990 Hawkridge (cited in Tondeur, van Braak \& Valcke, 2007) suggested that four rationales lay behind this emphasis on ICT, evident even then. While the terminology has changed and the educational policy focus has largely shifted from the installation of hardware and the development of technical skills to an emphasis on e-learning, these core rationales have retained currency. They are:

1. an economic rationale: the need for a skilled work force;

2. a social rationale: developing responsible and well-informed citizens;

3. an educational rationale: ICT is seen as a tool for improving teaching and learning;

4. a catalytic rationale: ICT is seen as a key catalyst for educational innovation.

More recently greater emphasis has been placed on educational benefits for students, within a 21st century learning framework. These benefits include greater student independence, engagement and motivation, as well as better interactions between teachers and students. (Falloon, 2010) Further, as digital technologies have become increasingly ubiquitous in the wider community, the desirability of their use in schools has become, apparently, a self-evident truth. There is no denying there are strong arguments for utilising the tools that students use in their daily lives to enrich their educational experiences, for ensuring their education is authentic and relevant.

Evaluative research we have undertaken over the past decade, concerning the use of digital tools in New Zealand schools, suggests that while digital technologies are widespread in many schools, their potential to impact significantly on how students participate in and experience learning, as enunciated in the strategic discourse and other literature regarding the integration of ICT, has not been realised. Schooling appears to remain largely impervious to the potential of digital technologies for innovation and transformation; the vast majority of schools around the globe continue in their traditional form (Lee \& Finger, 2010). The inclusion of digital technologies in classrooms does not automatically equate to changes in teaching practices; they do not lead to widespread educational reform of themselves. Digital tools are generally used to replace or supplement more traditional tools, rather than for innovation in classrooms (Ward, 2009). The reasons for this lack of success, in terms of innovation and educational reform, may lie in the policies themselves, in the official discourse that emanates from government, rather than within the schools or technologies.

Throughout this article the term policy has been used in a very broad sense to refer to discourse and documentation that emanates from the New Zealand Ministry of Education, rather than legislative policy. New Zealand has one of the most devolved governance models in the world with considerable autonomy given to schools (Robinson \& Ward, 2005). One of the consequences of this model has been a lack of mandated policy in education. Rather, the Ministry provides strategic and operational 
documents outlining guiding principles, goals and purposes regarding schooling. The Ministry also design and fund a range of initiatives aimed at supporting schools to implement these goals and purposes. The extent to which schools implement these "policies" is largely voluntary. To avoid confusion with other jurisdictions and to reflect that these are government documents reflecting strategic intent, the term "policy" has been used throughout this article, despite these not being legislative policy in the true sense of the word.

\section{Implementing national policy}

This article is based in the context of New Zealand ICT educational policy. The New Zealand situation is not unique and the issues facing New Zealand have resonance globally, as evidenced in the international literature on the integration of ICT. As such New Zealand can be viewed as a single case of the implementation of ICT policy in order to reform teaching and learning in schools. The discussion in this article, therefore, has salience in other jurisdictions.

National educational policy can be seen as being implemented at three distinct levels. The first, strategic policy, is defined in this article as documentation or discourse providing high level statements of desired goals and purposes. These are visionary and describe an end state. They are largely theoretical, providing guiding principles rather than practical suggestions. Such policy exists both at a generic (national educational strategic policy) and at an area specific level (in this instance ICT strategic policy). The second, operational policy, is of a practical nature and is focussed on the means by which these goals and purposes can be attained and tends to be area specific only. These are the initiatives which the Ministry develops and funds in order to operationalise their strategic intent. Generally the delivery and evaluation of these initiatives is contracted to external providers who report to the Ministry through milestones and other reports. The Ministry often has little direct contact with the schools themselves. The third level is that where policy is actually implemented in classrooms. The extent to which this occurs is dependent on the willingness of the schools involved. There is little, if any, consequence for those schools who do not meet the expectations of the Ministry regarding strategic intent and generally no formal requirement for them to participate in specific initiatives.

The level of coherency between strategic and operational policy and their enactment in class is considered with relation to the utilisation of digital technologies to enhance both the learning experiences and outcomes of students. Mee (2007) raises the question of the extent to which there is a coherent policy framework in the United Kingdom and the same question is asked here of the New Zealand context.

\section{Strategic policy into practice: A translation issue?}

Two possible reasons have been offered for the failure of ICT policy to drive instructional reform. The first is that the failure is a result of inadequacies in the policy itself (Selwyn, 1999); the second is that there is inadequate implementation of the policy at a school and/or classroom level (Spielvogel, 2001). It is our contention that these reasons are too simplistic for something as complex as policy development, implementation and enactment which is both "dynamic and messy" (Hodgson \& Spours, 2006, p 689). What is not acknowledged are the differing levels and nature of policy, or the influence of context and the multiple players involved in the policy process, nor the impact of individual schools and teachers as mediators of policy. 
The failure of strategic policy implementation, we suggest, lies in the inadequacy of the theory of action for implementing ICT strategic policy as evidenced in operational policy. A policy's theory of action is derived from "the particular rationales that are articulated by policy actors and the internal logics of the policy" (Malen, Croninger, Muncey \& Redmond-Jones, 2002, p.114).

Between the two extremes of the policy process (educational strategic policy and teaching and learning), lies a black box not dissimilar to that which sits between teaching practice and student learning (Black \& Wiliam, 1998; Stein \& Spillane, 2005). Within this black box, the discourse in strategic policy is translated into practice through operational policy. If this translation is inaccurate or incomplete, strategic policy is unlikely to be fully implemented, in the sense that the desired outcomes are unlikely to be achieved. The reason for the failure to achieve the strategic outcomes of 21 st century learning and pedagogical reform through the integration of digital tools can be found in this black box.

Figure 1 is a detailed representation of this complex, translation process from national strategic policy through to teaching and learning, and highlights what occurs within the black box and how much room there is for dilution, misrepresentation and loss of vision and/or goals.

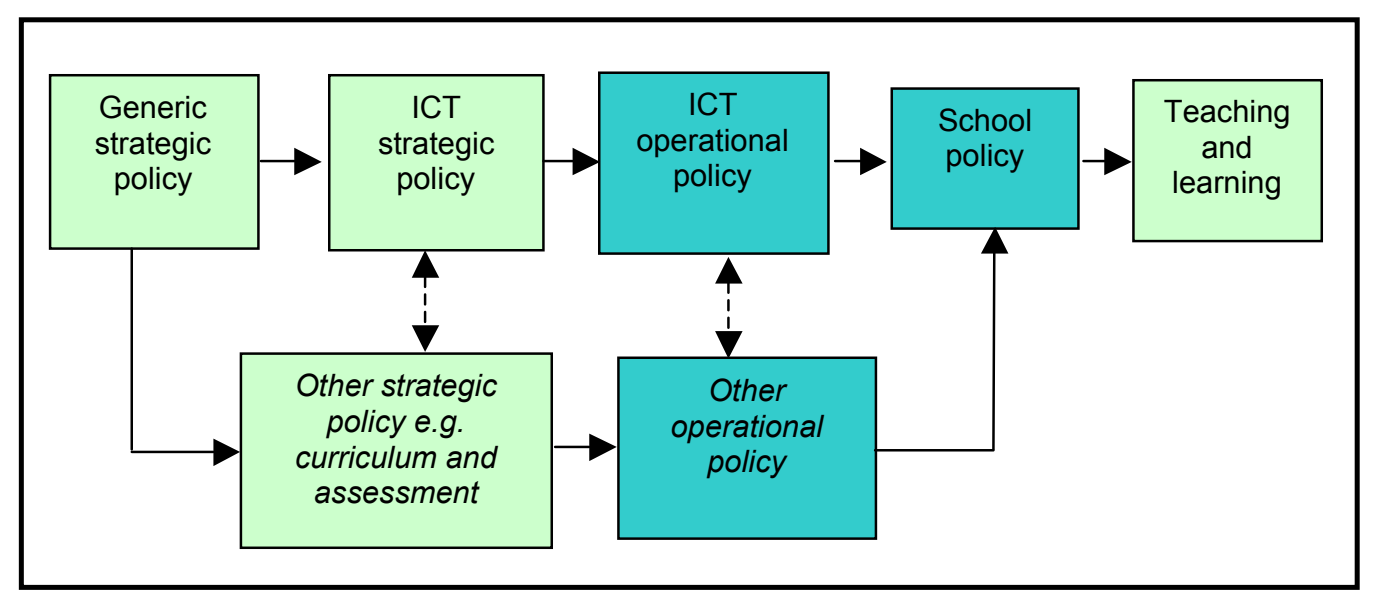

Figure 1: The translation of strategic policy into action

As well as illustrating what sits within the black box the diagram also depicts the need for alignment within and across a number of policy strands, particularly assessment, curriculum, pedagogy and ICT. Significantly, this diagram depicts the sites where there is room for policy disconnects through a lack of coherence and/or clarity within a policy area such as ICT.

We argue that the poor translation of ICT strategic policy into teaching and learning can be seen as arising from a lack of coherence and alignment within and across educational policies and the initiatives designed to implement them. This disconnect has led to a series of mixed messages and a lack of clarity for those entrusted with enacting policy - school leaders and classroom teachers. The reason for this lack of coherence and alignment appears to be a simplistic and silo-like operational policy view that does not take into account the complexities of either the policy context or the 
educational context within which strategic policy is to be implemented. What is needed is both horizontal coherence and vertical alignment as shown in Figure 2.

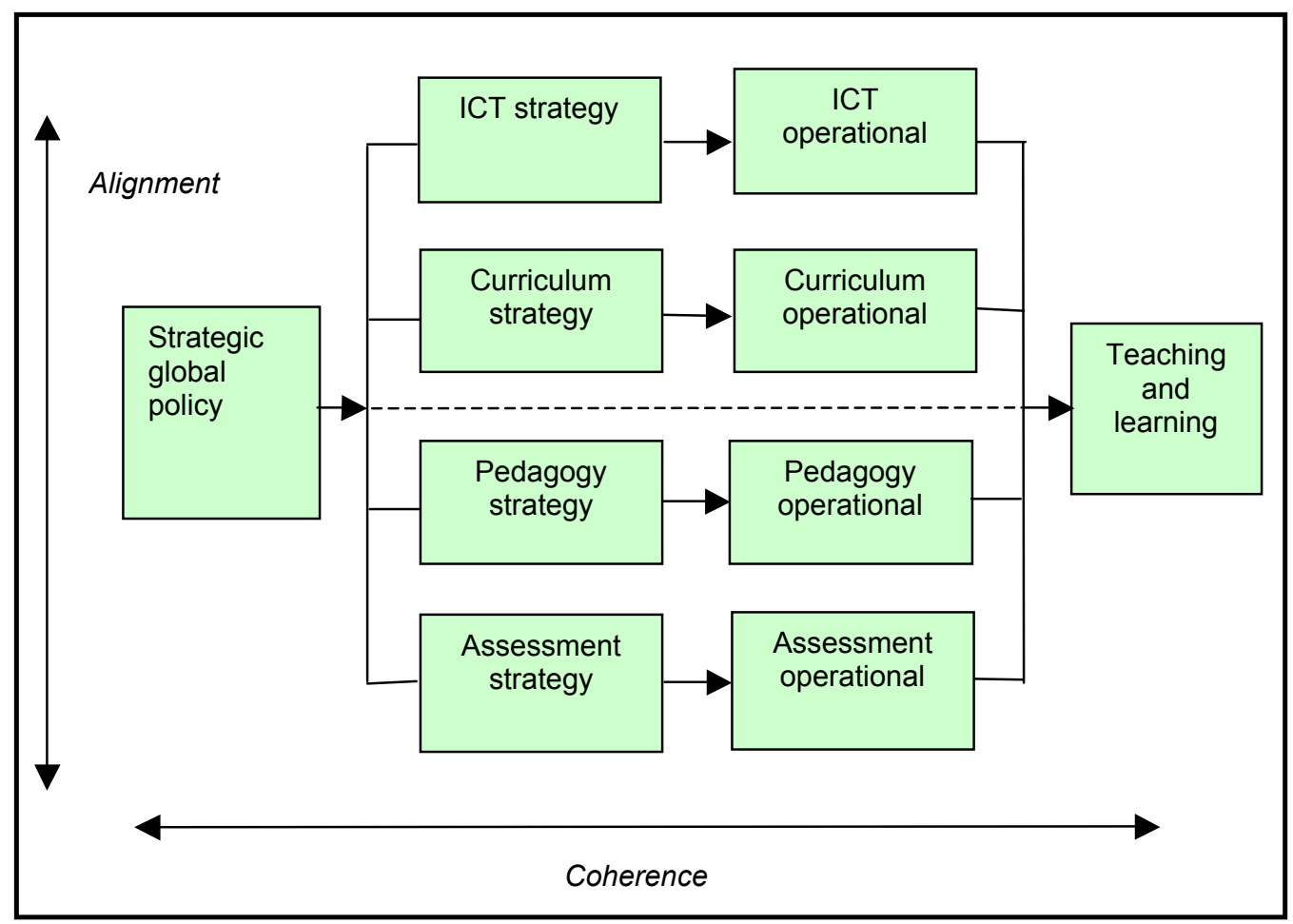

Figure 2: Horizontal and vertical policy enactment

In subsequent sections the case for horizontal coherence is argued through a consideration of the enactment of ICT policy in New Zealand schools. Firstly, ICT policy is placed in the broader context of New Zealand's generic educational strategic policy in order to understand its positioning and relevance. An important dimension of legitimacy is that enactment of ICT policy should facilitate the attainment of the broad educational goals set out in generic strategy documents. Both ICT strategic and operational policy are then considered before their implementation in schools, as evidenced in teaching and learning, is discussed.

In this article we do not consider the issue of vertical alignment except to highlight its importance and to underline that horizontal coherence alone will not bring about the required reform. Without vertical alignment, that is both explicit and practical, there will continue to be mixed messages and tensions for school leaders and teachers attempting to implement a diverse range of policy.

\section{Generic strategic policy within the New Zealand education system}

The three key strategic documents for compulsory schooling within the New Zealand education system are the Educational Priorities for New Zealand (Ministry of Education, 2003), the Schooling Strategy (Ministry of Education, 2005b) and the New Zealand Curriculum document (Ministry of Education, 2007). The extent to which there is 
consistency and coherence between the strategic goals and priorities found in these documents and the goals and priorities of ICT operational policy is salient.

Combined, these documents highlight the centrality of school reform and the increasing range of desired outcomes for students within the discourse to be found in New Zealand global educational strategy documents. Within these documents New Zealand education institutions are described, amongst other things, as needing to "adapt quickly to the changes occurring in our society and economy, embrace new ways of doing things, be technologically capable, and focus on continual improvement in learning and teaching" (Ministry of Education, 2003, p.8). One of the key priorities for the New Zealand government is stated as being to build an education system that equips New Zealanders with 21st century skills. In the New Zealand curriculum document, e-learning is described as having "considerable potential" to support the teaching practices espoused within the curriculum as consistently having a positive impact on student learning (Ministry of Education, 2007).

Given the centrality of instructional reform and 21st century learning in these documents, ICT policy discourse, both strategic and operational, could be expected to have a strong coherence and fidelity with global educational strategic policy discourse in New Zealand.

\section{ICT policy within New Zealand: Strategic and operational}

ICT policy in New Zealand is enacted across the various levels depicted in Figure 3. Two of the levels depicted in this diagram are considered in this section: ICT strategic policy and operational policy. Implementation is considered in the subsequent section.

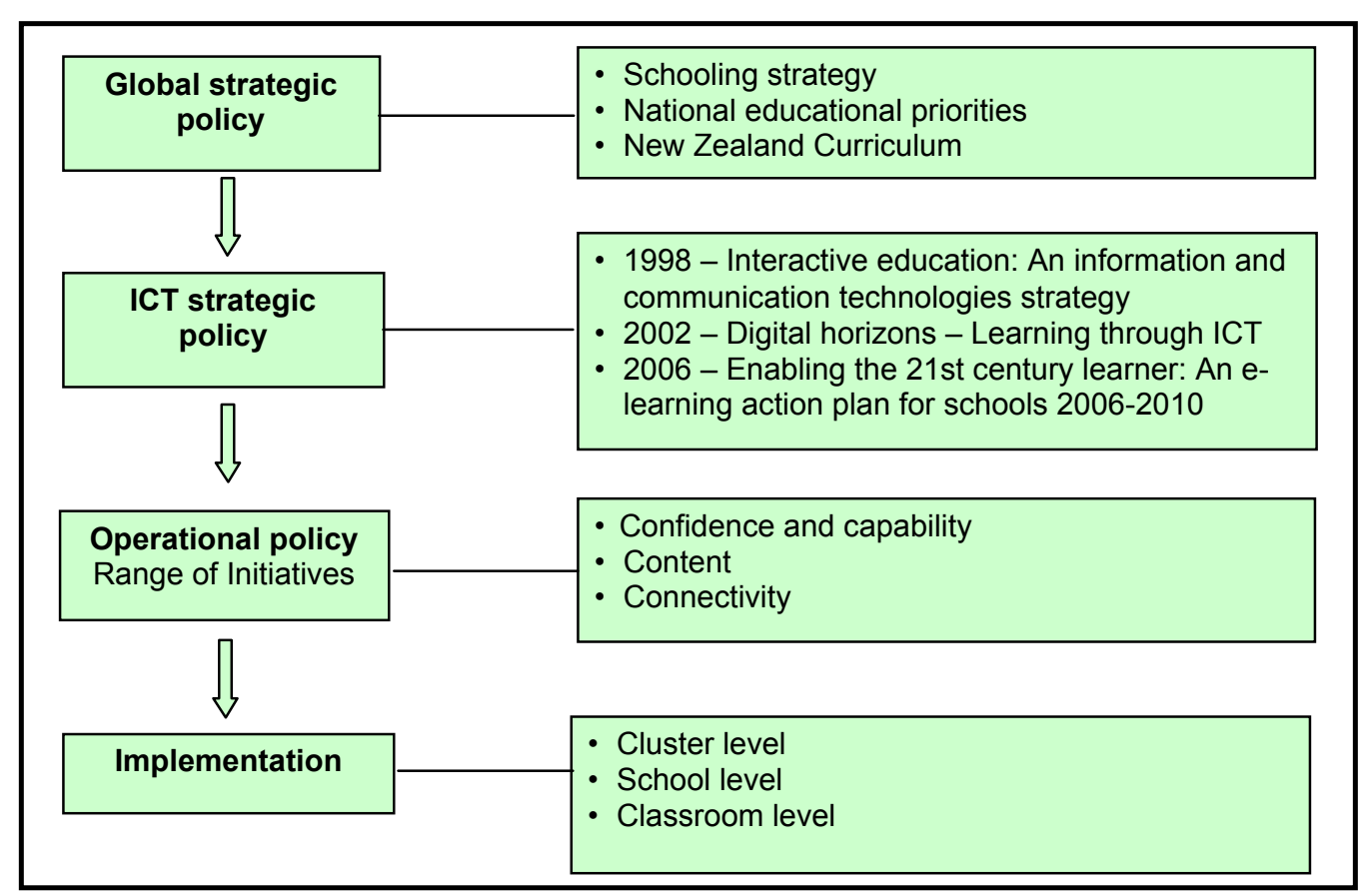

Figure 3: ICT policy enactment within the New Zealand context 


\section{ICT strategic policy}

There have been three phases in the development and implementation of ICT strategic policy in New Zealand. The first ICT strategy document for New Zealand schools was released in 1998 with the goal of building infrastructure and school capability. This infrastructure thrust was followed in 2002 by the Digital horizons strategy: Learning through ICT. This strategy focused on the challenge of integrating ICT more fully into curriculum practice. Most recently an e-learning action plan entitled Enabling the 21st century learner (Ministry of Education, 2006) was developed.

This action plan shifted the focus of ICT integration further towards notions of 21st century learning and a learner-centred education system, and was designed to make explicit the links between global strategic policy as stated in the Schooling Strategy and the Educational Priorities and e-learning. The stated expectation is that the e-learning action plan "will contribute directly to the goals and priorities of the Schooling Strategy" and also to the "Government's overarching goal to build an education system that equips New Zealanders with 21st century skills through the increased use of e-learning in schools" (ibid p.4).

Within this document, and those preceding it, ICT strategic policy can be seen to directly link to, and be coherent with, global NZ educational policy in terms of its desire for school change and for a broad and enriched view of learning. The next section considers the degree of fit between ICT strategic policy and operational policy.

\section{ICT operational policy}

In 2005, the Ministry of Education distributed a booklet outlining all ICT initiatives designed to facilitate 21st century learning in early childhood centres, schools and tertiary institutions (Ministry of Education, 2005a). A total of 40 initiatives were grouped under the headings: confidence and capability (17 initiatives), content (13 initiatives) and connectivity (10 initiatives). These initiatives were designed to develop a supporting framework for the enactment of ICT strategic policy. They provide schools with access to online resources and professional learning communities, professional development and infrastructure. What they do not do is provide schools with an understanding of the educational and catalytic rationales underpinning policy. Nor are there any initiatives explicitly aimed at changing the nature of teaching and learning practices at a deep level. Implementing these initiatives could result in little more than changes to how teaching occurs with the same practices being implemented using different tools. In this way practice is replaced or supplemented, not changed. Innovation does not automatically occur.

The theory of action underpinning operational policy seems to operate on a "leap of faith" basis which could be described as a 'build it and they will come' model. It presumes a level of "buy-in" and understanding from schools of policy expectations with regard to innovation and reform, rather than replacement or supplement, that would not appear to be present in many instances. It also appears to presume that schools will understand the connections between these initiatives and the strategic intent they are designed to operationalise. Figure 4 illustrates this model.

At face value this flow appears to be logical, particularly given the devolved governance model within New Zealand. There is no denying that for teachers to use 
digital tools in their classrooms it is essential that they have access to and the capacity to use digital tools. Without a critical level of both, integration cannot occur. However, the lack of both integration and changes to teaching and learning evident in much of the research suggests that this logic is flawed.

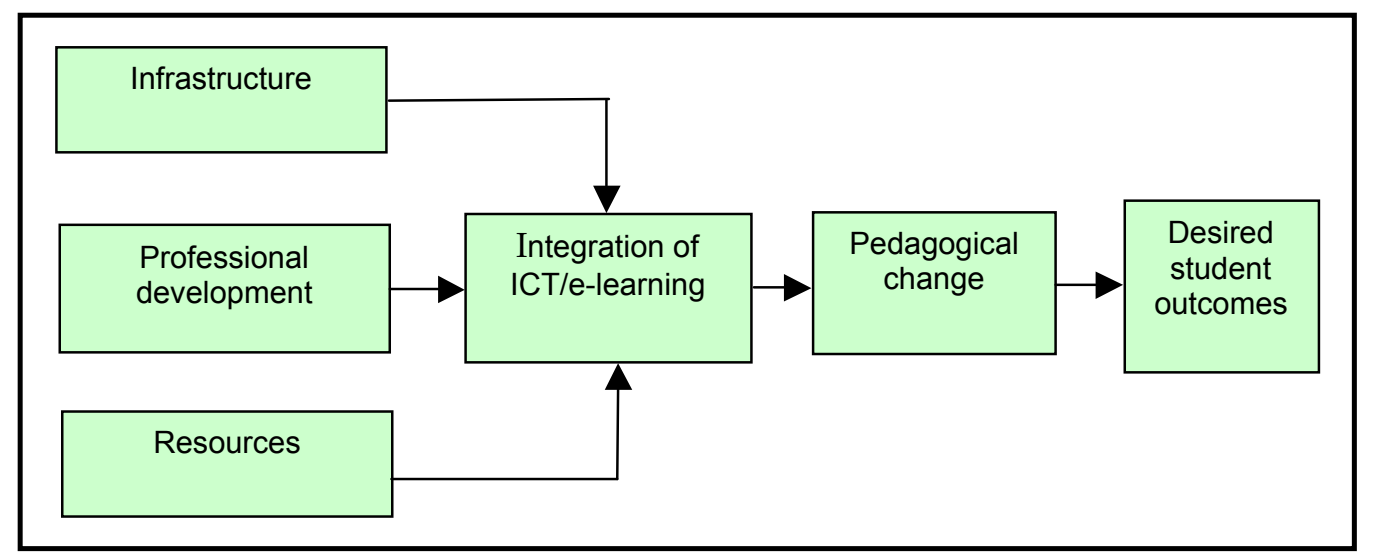

Figure 4: ICT policy theory of action model

One possible flaw is that this theory of action does not provide teachers, at least directly, with an opportunity to learn through the implementation of ICT policy: to learn about the strategic rationales underpinning it and how to implement strategic policy in their classrooms. It would appear that many school communities have not made the links themselves between operational policy and strategic policy and understood the implicit desired outcomes that lie beneath operational policy. The implication is that while strategic policy discourse may not be flawed, the theory of action for its implementation, as evidenced in operational policy, is. The leap of faith has not occurred.

Research into policy implementation in literacy and numeracy (Cohen \& Hill, 2000; Spillane, 1999; Spillane \& Jennings, 1997) suggests teachers are, in fact, key mediators in the successful implementation of policy. For fidelity to policy to occur, teachers need to be seen as "learners from policy rather than a vehicle for putting ideas into practice" (Spillane \& Jennings, 1997, p. 478). It is questionable whether the initiatives outlined in this section provide for this.

This, along with the extent to which there is fidelity to policy, will now be considered in more depth through a brief discussion of three specific initiatives.

\section{The implementation of policy: A question of fidelity}

In this section, results from the research evaluating three ICT initiatives are considered briefly, in order to illustrate both the extent and nature of the implementation of ICT operational policy. These initiatives: the provision of laptops for teachers (TELA), the funding of ICT professional development clusters (ICTPD) and the development of the FarNet online learning community, were chosen because of the level of evaluation they have been subjected to and the extent to which they are representative of the type of initiative being implemented by the New Zealand government. 


\section{The TELA Initiative}

The TELA initiative provides teachers with the opportunity to lease a laptop for a period of three years. Government funding meets up to two-thirds of the total cost for leasing, while schools or individual teachers meet the balance. Schools are expected to provide 40 hours of professional development funded through their existing operating grants, as well as to provide additional ICT infrastructure and technical support.

The goals and expectations of this initiative are twofold. It aims to enable teachers to develop new ICT skills, access online professional development, and create and access quality curriculum and assessment resources. It also aims to provide schools with an additional resource to support their ICT development program; an opportunity to motivate teachers who have yet to engage with ICT and a tool to support professional development initiatives.

Of all three initiatives, TELA has the most narrowly defined goals with no mention of school reform or 21st century learning. In fact, there is no direct mention of student learning in the goals. The outcomes desired are all teacher focussed. This would suggest a lack of explicit coherence between this initiative and overall strategic policy. The links between the TELA scheme and the educational priorities are certainly not obvious.

Data for the TELA evaluation were gathered through two surveys, teacher logs, group and individual interviews, and classroom observations. Findings show an increase in professional and administrative uses such as creating resources and searching the Internet or completing student reports in electronic format. Data also suggest that, for some teachers, the laptop enables them to make better use of other ICT infrastructure in the school. Overall, it would appear that the laptops offer teachers more opportunity but, correspondingly, more need to develop skills. Their portability and increased functionality, compared to other school computers, means that teachers use computers more widely than before.

Certainly, teachers expected the laptops to have an impact in the area of skill development and, in the first six months of ownership, reported a relatively large impact. They noted the value of it for professional development and how, for some, it had motivated them to do things they had not previously tried. Several teachers describe the laptops as the "best professional development I have ever had." With resource development, teachers reported at the outset that this was one area where they were already using computers. It is not clear the extent to which the laptops have allowed for a greater quality of resource, rather than quantity per se. Comments made during the focus groups, do however, suggest a positive shift in the type and quality of resource.

Interestingly, there appeared to be an unintended, and certainly indirect, outcome of the provision of laptops. While the overall Ministry of Education objective for the initiative does mention increased use in teaching and learning, the emphasis is, arguably, more on professional and administrative tasks than facilitating pedagogical change. However, the findings from both the interviews and classroom observations would suggest that the laptops are enabling teachers to change what happens in their classroom and to make greater use of other computers in the school for student learning. This is an important finding in that it suggests coherence with strategic 
policy in a way that was not made explicit in operational policy. In this instance, the leap of faith may be working, at least in some contexts.

There is a rider, however. Research suggests that teachers will enact policy when it is consistent with their values and beliefs (Kennedy, 2004). The TELA evaluation was undertaken in primary schools and it may well be that primary school pedagogies and cultures are more in line with desired strategic policy outcomes than secondary. Indeed, the ICTPD evaluation does suggest there are differences in outcomes between the two schooling levels and that primary teachers are more likely to use ICT in classroom practices (Sahin \& Ham, 2010).

The conclusions that can be reached, based on these findings are, firstly, that TELA as an operational policy initiative has validity. The theory of action underpinning the provision of laptops to teachers would appear to be sound and appropriate with regards to achieving the stated operational goals. Secondly, it would appear that there is fidelity to this operational policy in implementation. The goals and expectations of the teachers seem to support those of the Ministry and the laptops are having an impact on teacher professional lives and classroom practices.

What is less clear, though, is the fidelity of this policy initiative to the overarching strategies and policies of the Ministry of Education. The objectives of the TELA initiative do not, at least explicitly, include ideals of school reform and the improvement of outcomes for students. Nor do they mention the ideas of 21 st century learning and meeting the needs of the knowledge age. Questions still remain as to whether the TELA initiative is meeting these broader education goals. While it would seem that there are some instances where the initiative does this, these appear to be almost serendipitous.

\section{The ICTPD initiative}

The ICTPD initiative, rather than providing infrastructure with professional development as one of the conditions, as the TELA initiative does, focuses solely on professional development for teachers. Clusters of schools across New Zealand receive professional development in the use of ICT to support teaching and learning. Each cluster has a lead school responsible for leading and managing the program for their cluster. The lead schools and clusters are selected on a contestable basis and funded for three years.

The outcomes for this initiative are much more comprehensive than those of the TELA project and do include innovation in educational activities and the provision of quality, ICT-mediated learning experiences for students; as well as a recognition that teachers need to understand the educational benefits of ICT. Again, though, the main aim appears to be an increase in teacher skill and integration of ICT through the development of resources and strategies. There is no explicit mention of the broader goals of participation in the knowledge age, of 21st century learning, or even of pedagogical reform. Thus, as with the TELA initiative, there appears to be a gap between the clearly espoused goals and expectations of educational and ICT strategy discourse and those of operational policy discourse. It is left to schools and teachers to read between the lines and understand there is a reform intent underpinning these initiatives. 
Furthermore, there is evidence to suggest the outcomes listed above will not necessarily promote pedagogical reform, in that local enactment of policy depends not only on the ability of teachers to change practice and to teach in ways consistent with the reforms, but also on their willingness and capacity to learn (Spillane, 1999). Whether this is achieved through the ICTPD initiative would depend largely on the type of professional development provided, and the extent to which it is focussed on change; and on the levels of engagement and motivation of the teachers involved.

The primary data collection method for the ICTPD evaluation was the use of large scale surveys providing self-report data over time. Case studies were also conducted that included focus groups and classroom observations. Unlike the other two initiatives, highlighted in this article, we have not been involved in the evaluation of the ICTPD clusters. We have accessed the 2010 evaluation report to inform this section (Sahin \& Ham, 2010).

Findings from the ICTPD evaluation, as in TELA, showed a reported increase in teacher skill level and in their confidence in using computers. At the end of the program the great majority of teachers reported moderate to high levels of skill in fundamental areas such as file management, word processing and spreadsheets. Increases were also reported in areas such as graphics, multimedia and the Internet. However, the proportions of respondents reporting high levels of skill in these latter areas were much lower. It should also be noted that most teachers reported their skill levels were already high prior to the ICTPD program. Increases in confidence in using ICT in the classroom were marked, rising from $34 \%$ to $77 \%$ of respondents reporting they were confident or very confident in this area, suggesting an increased likelihood of the use of ICT in classrooms. However, gains in skills and confidence do not automatically translate to changes in practices or in the way students experience learning; they may simply increase what is already occurring such as word processing and Internet searches. Quantity of use should not be mistaken for quality of use with regard to student learning experiences.

Further, when respondent understandings of the educational benefits of using ICT in the classroom were analysed there were only three categories of response in which more than $10 \%$ of responses were grouped. These were related to facilitating more effective learning of specific curriculum content and curriculum objectives (28\%), making learning more engaging and interesting (25\%), and fostering more independence and agency in student learning (14\%). Key social and educational benefits related to 21st century learning did not feature to any marked extent amongst the responses with most accounting for less than 5\% of the responses. Around $28 \%$ of comments suggested that participation in the ICTPD programme had challenged and changed respondents' pedagogical perspectives and understandings. Of this group only 50\% reported trying out new and different teaching approaches in the classroom. Notably, primary teachers were more likely to see the program as contributing new insights and ideas than secondary teachers. This would seem to support the positive findings from the TELA initiative discussed earlier, compared with FarNet (which involved predominantly secondary schools).

These findings would suggest that the extent to which the individual goals of the initiative were achieved is variable. Certainly, there is reportedly both increased teacher use of ICT and increases in teacher skills and confidence. The extent to which there is a change in practice or a move towards 21 st century learning is less clear. 
While there is some fidelity to policy, there are also areas where policy goals are not being met. This may be due to the somewhat flexible nature of the initiatives and the extent to which schools are free to choose their own desired outcomes. Those outcomes, particularly with reference to classroom practice, one could presume, are likely to be closely matched to their current practice and their perceived needs. That is, what they choose to focus on is probably determined by what Spillane (1999) refers to as their "zone of enactment", which is the zone "in which teachers notice, construe and operationalize the instructional ideas advocated by reformers" (p.144), in this instance, policy makers. These enactment zones may be individual and mostly private and, as such, can explain the differential levels of policy implementation seen in these initiatives.

\section{The FarNet initiative}

FarNet is one of four Digital Opportunities Pilot Projects introduced between 2001 and 2003. The four projects shared a common goal of raising student achievement and increasing student participation in school, particularly in the areas of mathematics, science and technology. However, each of the projects was unique in the way in which this goal was approached (Rivers \& Rivers, 2004).

The approach utilised in the Far Net project was the development of an online learning community for teachers and students incorporating ten schools in the Far North of New Zealand. The intention was to provide for collaboration and the sharing of resources. In order to establish this community, bandwidth was increased to the participating schools, hardware and software were supplied and a website set up, which was to act as the hub for the learning community. Again, a lack of explicit linkage with strategic policy is apparent in that there is no direct mention of the broader goals of ICT strategic policy or the educational strategy policy that is, supposedly, an umbrella for all such initiatives.

Data for the FarNet evaluation were gathered through surveys, individual and group interviews, document analyses and website monitoring. FarNet is arguably the most intensive initiative in terms of the comprehensive nature of its implementation. However, the outcomes are arguably limited. While teacher skill levels and access to technology were enhanced in the participating schools, there seems to have been little impact in terms of actual classroom practices within the schools or in the level of interaction among schools. The online professional learning community never became a viable, or sustainable, community and resources posted for sharing were limited both in nature and extent (Parr \& Ward, 2006).

As with the ICTPD initiative, the goals that participants reported for the FarNet program were largely met. Again, however, these were limited. The majority of participants $(58 \%)$ wanted to improve their own skills. The next most commonly reported goal was an increase in administrative use of ICT (13\%). Integration of ICT into the classroom was a goal of only $11 \%$ of participants. The most commonly reported goal is clearly not aligned with the policy goals underpinning the initiative itself and suggests a lack of coherence between the goals and expectations of teachers and those of the policy makers. Again, this is similar to the ICTPD initiative.

As with the other two initiatives, the goals and expectations of the teachers were the ones being met. There was reportedly a significant improvement in the level of skill 
and confidence in the use of ICT, both for personal use and for use in the classroom over the course of the FarNet initiative. The data suggest that there was, at best, a modest impact on respondents' teaching practices. That is while teachers were more skilled and confident this did not necessarily translate into changes in what was occurring in their classrooms. Not more than $10 \%$ of teachers ever reported a marked change in their teaching practice as a result of participation in the initiative. This may have been due to a lack of pedagogical content in the ICTPD generally and the fact that much of the professional development appears to have focused on workshops, despite the reported variation in teacher skills and confidence prior to the contract. As with the other initiatives, the most commonly reported increases in use were for administration and lesson planning and preparation.

A central desired outcome of the FarNet initiative was the development of an online professional learning community across the schools involved. As already mentioned, this never really occurred. At the end of the initiative only a few curriculum areas within the website had a significant number of resources posted and those that were had generally been posted by curriculum leaders. Teachers reported greater use of the Internet than of the FarNet site and there was little use of the website as a communication tool. The conclusion that can be drawn from this evaluation is that a number of factors have to be in place before a professional learning community can be created. These include a perceived, and agreed to, need for the community, a feeling of security or trust that would allow for a greater deprivatisation of practice and risk taking, and a collective responsibility for the community as a whole (Parr \& Ward, 2006).

\section{Conclusions: The extent of policy enactment}

While there are marked differences in these three initiatives in terms of both area of impact and in the nature of what is provided, the core desired outcomes for each were the same: increased teacher and school capacity in order to better enable the integration of ICT into teaching and learning practices. What integration should look like, what the desired outcomes of that integration are to be or even how digital tools should be used to promote the strategic goals of educational policy, including the ideals of 21st century learning, are not made explicit in initiative documentation.

In all three instances operational policy was largely implemented in the sense that infrastructure and professional development were respectively installed and provided. The use of digital technologies also increased in many instances, albeit often in limited ways. However, there appears to have been only limited influence at a strategic level in terms of policy outcomes that relate to 21st century learning and school reform. Where this did occur, it appears to have been largely serendipitous and may be due to teachers already having values and philosophies that align with strategic policy.

What is also apparent, through a review of the evaluation findings (Parr \& Ward, 2005, 2010; Sihan \& Ham, 2010), is the extent to which it is the goals and expectations of the teachers that were met rather than those of the Government. Where these matched those of the strategic policy developers, then there was fidelity to strategic policy.

This supports the view expressed by Kennedy (2004) that teachers will enact policy when it is consistent with their values and beliefs. Teachers, across these initiatives, who were utilising the digital tools provided in supporting 21st century learning were 
doing so because they valued such learning, not because they had been provided with the tools per se. This is an important distinction. McGarr (2009) suggests we should be considering the extent to which existing pedagogy changes ICT, rather than the more common view of ICT changing pedagogy, and this view would seem to be supported here.

It is also worth noting how operational policy goals and expectations became more diluted within the latest initiative, TELA. While the earlier initiatives did include some notion of innovation in educational activities in their goals and purposes the TELA initiative did not. The concern is the extent to which these goals and expectations are self-fulfilling limitations on the potential of digital technologies. To be avoided is a downward spiral of limited impact leading to limited expectations.

\section{Where to next?}

This analysis of educational policy and the enactment of ICT policy in New Zealand would suggest that, while there is fidelity to operational policy, the enactment of strategic policy is, at best, limited. Where it does occur, it appears to be due to individual teacher values and beliefs and their resultant expectations for ICT integration.

There appear to be three specific, and related, issues that need to be attended to. The first is a lack of obvious and clearly espoused coherence between strategic and operational policy. The goals and expectations of the Ministry, as shown in the three initiatives used as examples here, appear to be a diluted form of ICT strategic policy. The emphasis on 21st century learning and pedagogical reform in strategic policy shifts to one of increasing school and teacher capacity in terms of infrastructure and skills at an operational level. While these are needed for ICT integration they are not sufficient on their own, as shown by the limited integration and use of digital tools in ways consistent with strategic policy both in New Zealand and elsewhere.

As noted, the current theory of action for implementing ICT policy appears to be based on a leap of faith, the notion that if we build the structure educational practitioners will come (and embrace the ideals). Current international research suggests that most have not come! Thus, it could be said the ICT policy at an operational level is flawed. It has not made explicit enough what the desired outcomes of implementation are or what the rationales underpinning it are. Nor has it examined why teachers do what they do and addressed the constraints defining their current practice. Rather, ICT has been offered as a solution for what many teachers do not see as a problem: the need to transform teaching and learning.

Secondly, what are enacted are individual teacher and school goals and expectations. Where fidelity is achieved, these goals and expectations closely fit those of strategic policy. ICT policy is, therefore, not acting as a reform tool. At best it is enhancing the practice of those whose pedagogical values and beliefs already match those of policy. The implication is that ICT will not reform practice unless teachers are given the opportunity to learn from policy and unless teachers are willing and able to change their practice. This supports the idea that, while there is an implementation issue, the real problem lies not with the enactment of policy by teachers but the theory of action underpinning that enactment at a policy level. 
The final, closely related issue, is specific to decentralised governance jurisdictions. The highly devolved governance model within New Zealand means there is little direct control over what schools and teachers are doing, except through national assessment and curriculum directives, yet digitalisation sits outside these. The Government's role is one of support, of strategic leadership and of funding the various initiatives. Schools, however, carry the responsibility for determining the priorities for development in their own settings. The result is that teachers and schools have been able to define their expectations in a limited manner, as apparently have those charged with developing operational policy.

Most significantly it means that the power of schools and teachers as mediators of policy is even more pronounced than it may be in other schooling systems and jurisdictions, and the necessity for clarity of expectations and coherence across policy is even greater.

\section{References}

Black, P. \& Wiliam, D. (1998). Inside the Black Box: Raising standards through classroom assessment. Phi Delta Kappan, 80(2), 139-148

Cohen, D. K. \& Hill, H. C. (2000). Instructional policy and classroom performance: The mathematics reform in California. Teachers College Record, 102(2), 294-343.

Falloon, G. (2010). Learning objects and the development of students' key competencies: A New Zealand school experience. Australasian Journal of Educational Technology, 26(5), 626-642. http: / / www.ascilite.org.au/ajet/ajet26/falloon.html

Hayes, D. (2007). ICT and learning: Lessons from Australian classrooms. Computers $\mathcal{E}$ Education, 49, 385-395.

Hodgson, A. \& Spours, K. (2006). An analytical framework for policy engagement: The contested case of 14-19 reform in England. Journal of Education Policy, 21(6), 679-696.

Institute for Professional Development and Educational Research (2002). Review of future-focused research on teaching and learning. Wellington: Ministry of Education, Research Division. http: / / www.educationcounts.govt.nz/publications / ict/5331

Kennedy, M. M. (2004). Reform ideals and teachers' practical intentions. Education Policy Analysis Archives, 12(13). http: / / www.eric.ed.gov:80 / ERICWebPortal/ contentdelivery / servlet/ ERICServlet?accno=EJ852298

Lee, M. (2010). The networked school communities today. In M. Lee \& G. Finger (Eds), Creating $a$ home-school nexus. Melbourne: ACER Press.

Lee, M. \& Finger, G. (2010). The challenge: Developing a networked mode of schooling. In M. Lee \& G. Finger (Eds), Creating a home-school nexus. Melbourne: ACER Press.

Malen, B., Croninger, R., Muncey, D. \& Redmond-Jones, D. (2002). Reconstituting schools: "Testing" the "Theory of Action". Educational Evaluation and Policy Analysis, 24(2), 113-132.

McGarr, O. (2009). The development of ICT across the curriculum in Irish schools: A historic perspective. British Journal of Educational Technology, 40(6), 1094-1108.

Mee, A. (2007). E-Learning funding for schools: a policy paradox? British Journal of Educational Technology, 38(1), 63-71. 
Ministry of Education (2003). Education priorities for New Zealand. Wellington: Ministry of Education.

Ministry of Education (2005a). Enabling the 21st century learner. Wellington: Ministry of Education. http:/ / www.minedu.govt.nz/ NZEducation/EducationPolicies / Schools / Initiati ves/ICTInSchools / ICTInitiativesAndProgrammes/EnablingThe21stCenturyLearner.aspx

Ministry of Education (2005b). Making a bigger difference for all students: Hangaia he huarahi hei whakarewa ake inga tauira katoa: Schooling Strategy 2005-2010. Wellington: Ministry of Education.

Ministry of Education (2006). Enabling the 21st century learner: An e-learning action plan for schools 2006-2010. Wellington: Ministry of Education.

http: / / www.minedu.govt.nz/NZEducation/EducationPolicies/Schools/Initiatives/ICTInS chools / ICTInitiativesAndProgrammes/EnablingThe21stCenturyLearner.aspx

Ministry of Education (2007). The New Zealand Curriculum. Wellington: Ministry of Education. http: / / nzcurriculum.tki.org.nz/

Parr, J. M. \& Ward, L. (2005). Evaluation of FarNet: Learning communities in the Far North. Report to the Ministry of Education, Wellington, New Zealand. UniServices, University of Auckland. http:/ / www.educationcounts.govt.nz/publications/ict/5767/evaluation_of_ project_farnet_learning_communities_in_the_far_north

Parr, J. M. \& Ward, L. (2006). Building on foundations: Creating an online learning community. Journal of Technology and Teacher Education, 14(4), 775-793.

Parr, J. M. \& Ward, L (2010). Laptops for Teachers: An evaluation of the TELA scheme in Auckland schools. Report to the Ministry of Education, Wellington, New Zealand. UniServices, University of Auckland.

http:/ / www.educationcounts.govt.nz / publications/ict/76808

Rivers, J. \& Rivers, L. (2004). A summary of the key findings of the Digital Opportunities Pilot Projects (2001-2003). A summary report to the Ministry of Education, Wellington, New Zealand. http: / / www.educationcounts.govt.nz/ publications/ict/5767/ 23745

Robinson, V. M. J. \& Ward, L. (2005). Lay governance of New Zealand Schools: An educational, democratic or managerialist activity? Journal of Educational Administration, 43(2), 170-186.

Sahin, S. \& Ham, V (2010). Outcomes for teachers and students in the ICT PD School Clusters Programme 2006-2008. A national overview report to the Ministry of Education, Wellington, New Zealand. Core Education. http: / / www.educationcounts.govt.nz/publications / ict/74460

Selwyn, N. (1999). Why the computer is not dominating schools: A failure of policy or a failure of practice? Cambridge Journal of Education, 29(1), 77-91.

Spielvogel, R. (2001). IBM's reinventing education grant partnership initiative. Individual site reports. New York: EDC/Center for Children and Technology. [verified 13 Apr 2011] http:/ / www.ibm.com/ibm/ibmgives/downloads/ReinventingEducationSiteEvaluations.pdf

Spillane, J. P. (1999). External reform initiatives and teachers' efforts to reconstruct their practice: The mediating role of teachers' zones of enactment. Journal of Curriculum Studies, 31(2), 143175 .

Spillane, J. P. \& Jennings, N. E. (1997). Aligned instructional policy and ambitious pedagogy: Exploring instructional reform from the classroom perspective. Teachers College Record, 98(3), 449-481. 
Stein, M. K. \& Spillane, J. (2005). What can researchers on educational leadership learn from research on teaching? Building a bridge. In B. Firestone \& C. Riehl (Eds.), Developing an agenda for research on educational leadership (pp. 28-45). Thousand Oaks: Sage Publications.

Tondeur, J., van Braak, J. \& Valcke, M. (2007). Curricula and the use of ICT in education: Two worlds apart? British Journal of Educational Technology, 38(6), 962-976.

Ward, L. (2009). Digitalising learning in secondary schools. SPANZ Journal, September. Auckland: Secondary Principals' Association of New Zealand.

Ward, L. \& Parr, J. M. (2010). Revisiting and reframing use: Implications for the integration of ICT. Computers E Education, 54, (113-122).

Authors: Dr Lorrae Ward is an independent contractor who undertakes a range of social policy research and evaluation. She has extensive experience as an educator and has been involved in the integration of digital technologies into education for many years as both a researcher and professional development facilitator. Her particular research interests lie in the use of digital technologies to enrich and enhance the learning experiences of students across all levels of schooling.

Dr Judy Parr is a Professor in the Faculty of Education at the University of Auckland. Her research program focuses on interventions that optimise student learning and development, particularly in literacy and she has long retained an interest in technology as a tool of social practice. She has published widely internationally: recent articles appear in Assessment in Education, The Curriculum Journal, Research Papers in Education, and Computers $\mathcal{E}$ Education.

Lorrae Ward PhD

93 Otuiti Rd, RD1 Tuakau, New Zealand. Email: lorrae@cyperus.co.nz

Professor Judy Parr, Faculty of Education, University of Auckland

Private Bag 92019, Auckland, New Zealand. Email: jm.parr@auckland.ac.nz

Please cite as: Ward, L. \& Parr, J. (2011). Digitalising our schools: Clarity and coherence in policy. Australasian Journal of Educational Technology, 27(2), 326-342. http: / / www.ascilite.org.au/ajet/ajet27/ ward.html 